\title{
Nodule Organogenesis and Symbiotic Mutants of the Model Legume Lotus japonicus
}

\author{
Krzysztof Szczyglowski, ${ }^{1}$ Robert S. Shaw, ${ }^{1,2}$ Judith Wopereis, ${ }^{1}$ Sue Copeland, ${ }^{1}$ Dirk Hamburger, ${ }^{1}$ \\ Beth Kasiborski, ${ }^{1}$ Frank B. Dazzo, ${ }^{3}$ and Frans J. de Bruijn, ${ }^{1,3,4}$ \\ ${ }^{1}$ Department of Energy Plant Research Laboratory, ${ }^{2}$ Department of Botany and Plant Pathology, \\ ${ }^{3}$ Department of Microbiology, ${ }^{4}$ Genetics Program, Michigan State University, East Lansing 48824-1312, \\ U.S.A. \\ Accepted 28 March 1998.
}

\begin{abstract}
A detailed microscopical analysis of the morphological features that distinguish different developmental stages of nodule organogenesis in wild-type Lotus japonicus ecotype Gifu B-129-S9 plants was performed, to provide the necessary framework for the evaluation of altered phenotypes of $L$. japonicus symbiotic mutants. Subsequently, chemical ethyl methanesulfonate (EMS) mutagenesis of $L$. japonicus was carried out. The analysis of approximately $3,000 \mathrm{M}_{1}$ plants and their progeny yielded 20 stable $L$. japonicus symbiotic variants, consisting of at least 14 different symbiosis-associated loci or complementation groups. Moreover, a mutation affecting $L$. japonicus root development was identified that also conferred a hypernodulation response when a line carrying the corresponding allele (LjEMS102) was inoculated with rhizobia. The phenotype of the LjEMS102 line was characterized by the presence of nodule structures covering almost the entire root length $\left(\mathrm{Nod}^{++}\right)$, and by a concomitant inhibition of both root and stem growth. A mutation in a single nuclear gene was shown to be responsible for both root and symbiotic phenotypes observed in the $L$. japonicus LjEMS102 line, suggesting that (a) common mechanism(s) regulating root development and nodule formation exists in legumes.
\end{abstract}

Nodules develop post-embryonically on the roots of legume plants as a result of localized morphogenic activity induced by lipochito-oligosaccharide signal molecules of rhizobial origin (Nod factors; Lerouge et al. 1990; Roche et al. 1991; Truchet et al. 1991; Spaink and Lugtenberg 1994; Ardourel et al. 1994; Yang et al. 1994). This complex and highly regulated process appears to be predominantly controlled by a plant morphogenic program (see Gresshoff 1993). However, multiple signals, derived from both the host plant and symbiotic bacteria, are needed in order to initiate and coordinate nodule organogenesis (for recent reviews see Hirsch 1992; Schultze et al. 1994; Mylona et al. 1995). A detailed examination of bacterial symbiotic genes and their protein products has led to the elucidation of a number of major components involved in symbiotic interactions (Schultze et al. 1994). This pertains especially to early symbiotic events that culminate in the synthesis

Corresponding author: Krzysztof Szczyglowski

E-mail: szczyglw@pilot.msu.edu of the rhizobial morphogenic Nod factors, and the initiation of nodule organogenesis (Schultze et al. 1994). Evidence for the involvement of a variety of other rhizobial factors in the control of root hair infection, final steps of nodule formation, and symbiotic nitrogen fixation has also been postulated and found (Truchet et al. 1980; Abe et al. 1984; Dazzo et al. 1991; de Billy et al. 1991; Welters et al. 1993; Dazzo et al. 1996).

A plethora of experiments have been carried out to investigate the role of the plant host in nodulation. The type of nodules that develop (determinate versus indeterminate) has been shown to be determined by the plant host (for a recent review see Schultze et al. 1994, and references therein). The extent of nodulation, as determined by quantifying the number of fully developed nodules on a single plant, has also been shown to be controlled by a plant-mediated process termed autoregulation (Bhuvaneswari et al. 1981; Pierce and Bauer 1983; Kosslak and Bohlool 1984). A collection of plant genes specifically expressed during nodulation, collectively referred to as nodulin genes (van Kammen 1984), has been isolated from various legumes (for a recent review see Mylona et al. 1995). However, the role of the majority of nodulin genes in nodulation remains to be determined (Csanadi et al. 1994).

Classical genetic approaches have been successfully applied to study the developmental program underlying nodule organogenesis and functioning. A large number of symbiotic variants have been isolated from different legumes, including agronomically important plants such as soybean, pea, alfalfa, and sweetclover (Jacobsen and Feenstra 1984; Carroll et al. 1985, 1986; Kneen and LaRue 1988; Duc and Messager 1989; Weeden et al. 1990; Utrup et al. 1993; Sagan et al. 1993, 1995; Kneen et al. 1994; Park and Buttery 1994; Banaben et al. 1995). Three basic categories of mutant phenotypes have been identified: (i) non-nodulation; (ii) ineffective nodulation and/or early senescence; and (iii) hypernodulation/nitrate tolerance. Most of the phenotypes described thus far have been shown to be controlled by single recessive genetic elements, yet dominant inheritance of the mutation underlying an unusual fourth class of symbiotic traits, Nar (nodulation in the absence of rhizobia), has also been reported (Truchet et al. 1989; Caetano-Anolles and Gresshoff 1991a; Caetano-Anolles et al. 1993). The isolation and characterization of different classes of symbiotic mutants have provided a solid basis for the development of novel concepts in symbiotic nitrogen fixation. It has been shown, for example, that shoot and root fac- 
tors can influence nodulation, and that shoot control of nodule initiation is epistatically suppressed by root-expressed mutations, resulting in a non-nodulation phenotype (Delves et al. 1986; Sheng and Harper 1997).

Autoregulation has been studied with split-root systems (Kosslak and Bohlool 1984) and shown to be mediated through systemic root-shoot interactions (Delves et al. 1986; Caetano-Anolles and Gresshoff 1991a, 1991b). These observations clearly suggest that the nodulation process is tightly integrated into the overall plant developmental program. This concept has been supported by the isolation of pleiotropic mutations affecting both symbiotic and nonsymbiotic properties (Jacobsen and Feenstra 1984; Delves et al. 1986; Day et al. 1986; Duc and Messager 1989; Kneen et al. 1994). Moreover, plant growth regulators (hormones) have been shown to be involved in nodulation (Hirsch and Fang 1994). For example, studies on the Pisum sativum nodulation-deficient sym5 mutant have implicated the plant hormone ethylene as a secondary signal in the inhibition of nodulation by both light and nitrate (Fearn and LaRue 1991; Lee and LaRue 1992). This hypothesis has been extended by the recent isolation of the Medicago truncatula mutant named sickle, which exhibits an increase in the number of persistent rhizobial infections (Penmetsa and Cook 1997). Interestingly, the same mutation confers insensitivity to ethylene, again suggesting an involvement of plant hormones in the signaling pathway controlling rhizobial infection (Penmetsa and Cook 1997).

However, the molecular mechanisms underlying the phenotype of most symbiotic loci identified to date remain unclear. In fact, none of the legume plant symbiotic genes identified by mutagenesis have been isolated. The large size and high degree of complexity of the genomes of soybean and other legume plants have impeded map-based cloning of symbiotic loci of the most well-studied legumes (soybean, pea, alfalfa, clover).

Therefore, we followed the proposal of Handberg and Stougaard (1992) to use the diploid legume Lotus japonicus, with a genome size only 4 to 5 times that of Arabidopsis thaliana, as a model legume system to study determinate nodulation and symbiotic nitrogen fixation (Handberg and Stougaard 1992; Jiang and Gresshoff 1993; Cook et al. 1997; Jiang and Gresshoff 1997). First, a phenotypic analysis of the nodulation process involved in the Mesorhizobium loti-L. japonicus symbiosis was carried out to provide a framework for the characterization of symbiotic mutants. Second, an ethyl methanesulfonate (EMS)-mediated mutagenesis program was initiated to identify a variety of genetic loci of this model legume involved in symbiosis.

\section{RESULTS}

\section{Morphological analysis of the $L$. japonicus nodulation process.}

In order to provide a basic framework for the analysis of L. japonicus symbiotic mutants, a detailed microscopical evaluation of the morphological features that distinguish different developmental stages of nodule organogenesis was carried out. For these studies, easily accessible root tissue for microscopical examination was required. Therefore, different conditions for robust plant growth and effective nodulation were evaluated (see Materials and Methods). The "pillow system" was selected, since both root growth and nodulation kinetics were found to closely resemble those observed for plants grown in vermiculite/sand mixtures (data not shown).

The morphological features of primary host infection were examined by a combination of brightfield and phase contrast light microscopy. These methods revealed that, as observed in other symbiotic systems, the mode of entry by $M$. loti was through infection threads initiated within deformed root hairs. Inoculation with the wild-type $M$. loti strain NZP2235 led to development of various root hair alterations, such as Had (hair deformation) and Hac (hair curling), that resulted in the formation of typical "shepherd's crook" structures (Fig. 1A). A
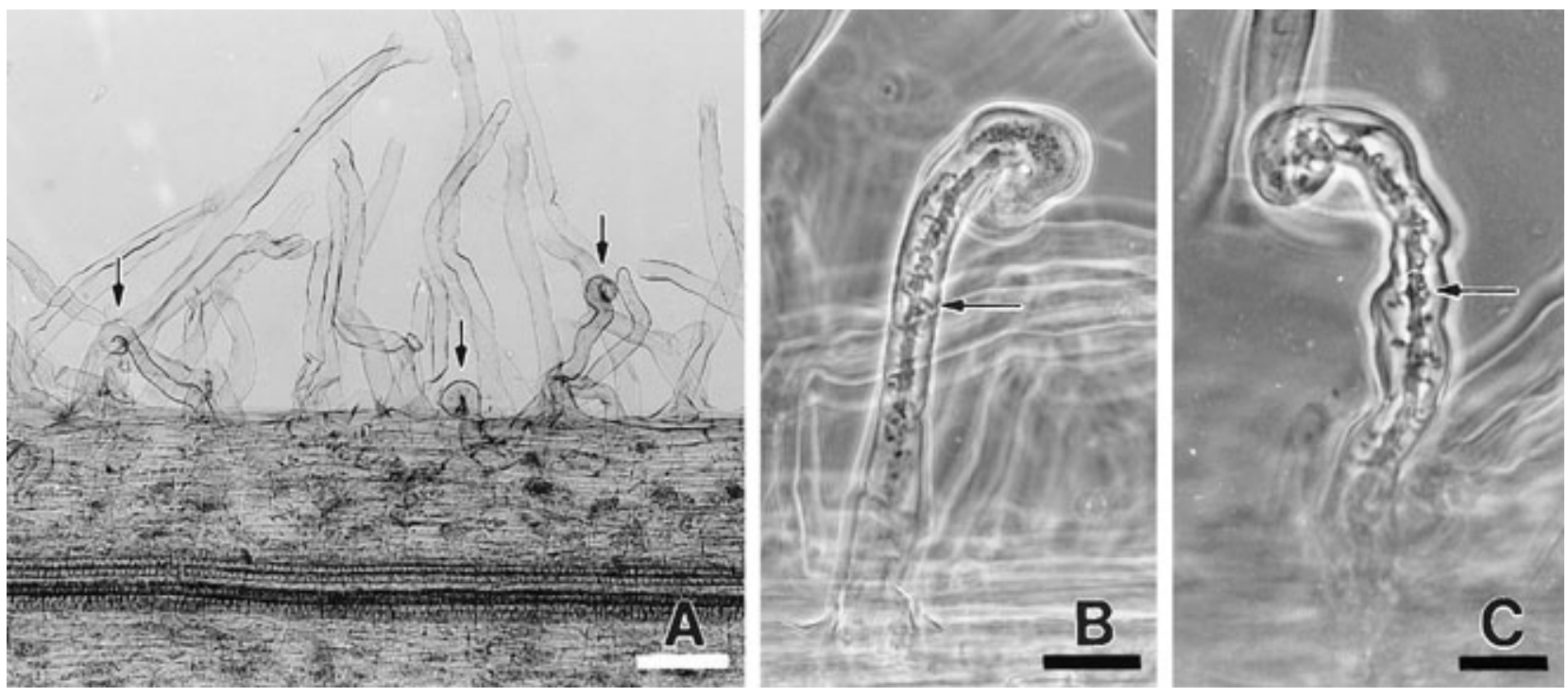

Fig. 1. Primary infection of Lotus japonicus roots inoculated with Mesorhizobium loti strain NZP2235. A, Brightfield micrograph of root hair curlings resembling shepherd's-crook structures (arrows). B-C, Phase contrast micrographs of the intracellular infection threads within curled root hairs. Arrows point to infection threads with papilla-like structures on their outer surface. Bar, $70 \mu \mathrm{m}(\mathbf{A}), 25 \mu \mathrm{m}(\mathbf{B})$, and $20 \mu \mathrm{m}(\mathbf{C})$. 
detailed examination of curled root hairs revealed the presence of bona fide intracellular infection threads originating at the tightly curled tip and extending the full length of the root hair

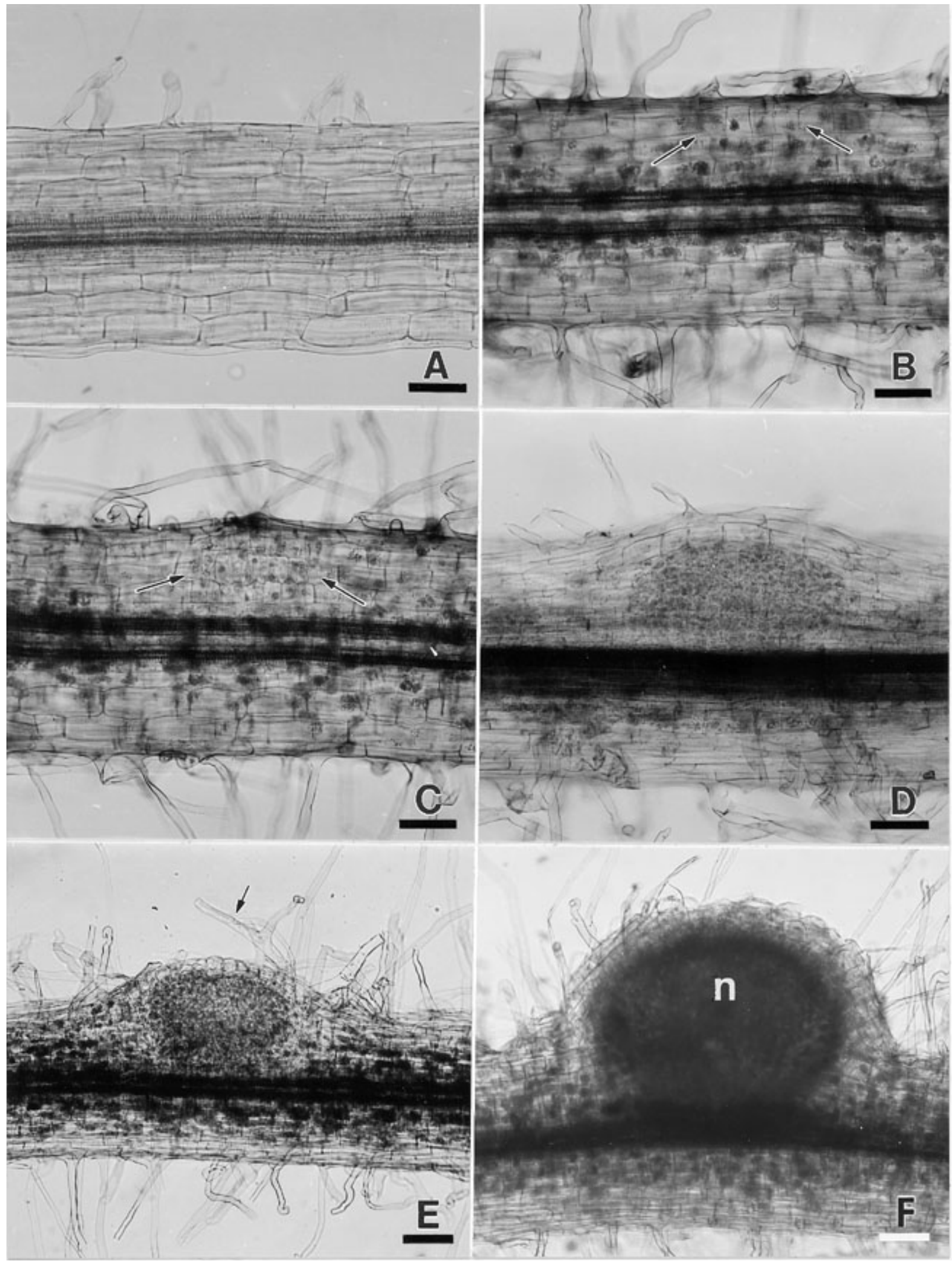

(Fig. 1B and C). "Papillae-like" structures were commonly observed on the outer surface of infection threads within $L$. japonicus root hairs (Fig. 1B and C). 
Brightfield microscopy of cleared roots revealed that the normal histology of the cortex consisted of three to four layers of cylindrical cells (Fig. 2A) that were typically $30 \pm 5 \mu \mathrm{m}$ in diameter and $138 \pm 26 \mu \mathrm{m}$ in length $(X \pm$ standard deviation, $\mathrm{n}$ = 44). Various developmental stages of M. loti-induced L. japonicus root cortical cell divisions leading to nodule formation are illustrated in Figure 2B-F. The earliest morphological indication of nodule initiation (Noi) was the formation of localized foci of anticlinal cortical cell divisions (Ccd's) typically found in the first outer cortical layer immediately beneath the site of primary host infection (Fig. 2B). The next stage of Noi observed involved more anticlinal Ccd's in several layers of the cortex within the same localized area of the root, before the epidermis began to bulge (Fig. 2C). Further development gave rise to a clearly defined meristem consisting of small, dark-staining cells constituting the nodule primordium, which induced a local bulging of the overlying root epidermis (Fig. 2D). The fourth distinguishable stage occurred when the epidermis split as the young nodule started to emerge from the root cortex (Fig. 2E). A fully emerged nodule is illustrated in Figure 2F.

The first nodules emerged from roots 5 to 7 days after inoculation, and on average 14 nodules per root could be observed by 21 days after inoculation. Root nodules initiated nitrogen fixation (acetylene reduction) approximately 10 days after inoculation (data not shown).

Stereomicroscopical examination of roots of L. japonicus plants 21 days after inoculation showed that two distinct types of mature nodules exist: the typical spherical nodule and a less common lobed nodule (Fig. 3A). Brightfield microscopy of semithin longitudinal sections of spherical nodules revealed a typical determinate nodule histology, including a large circular central area corresponding to the infected (bacteroid) zone, surrounded by a concentric layer of uninfected nodule cortex
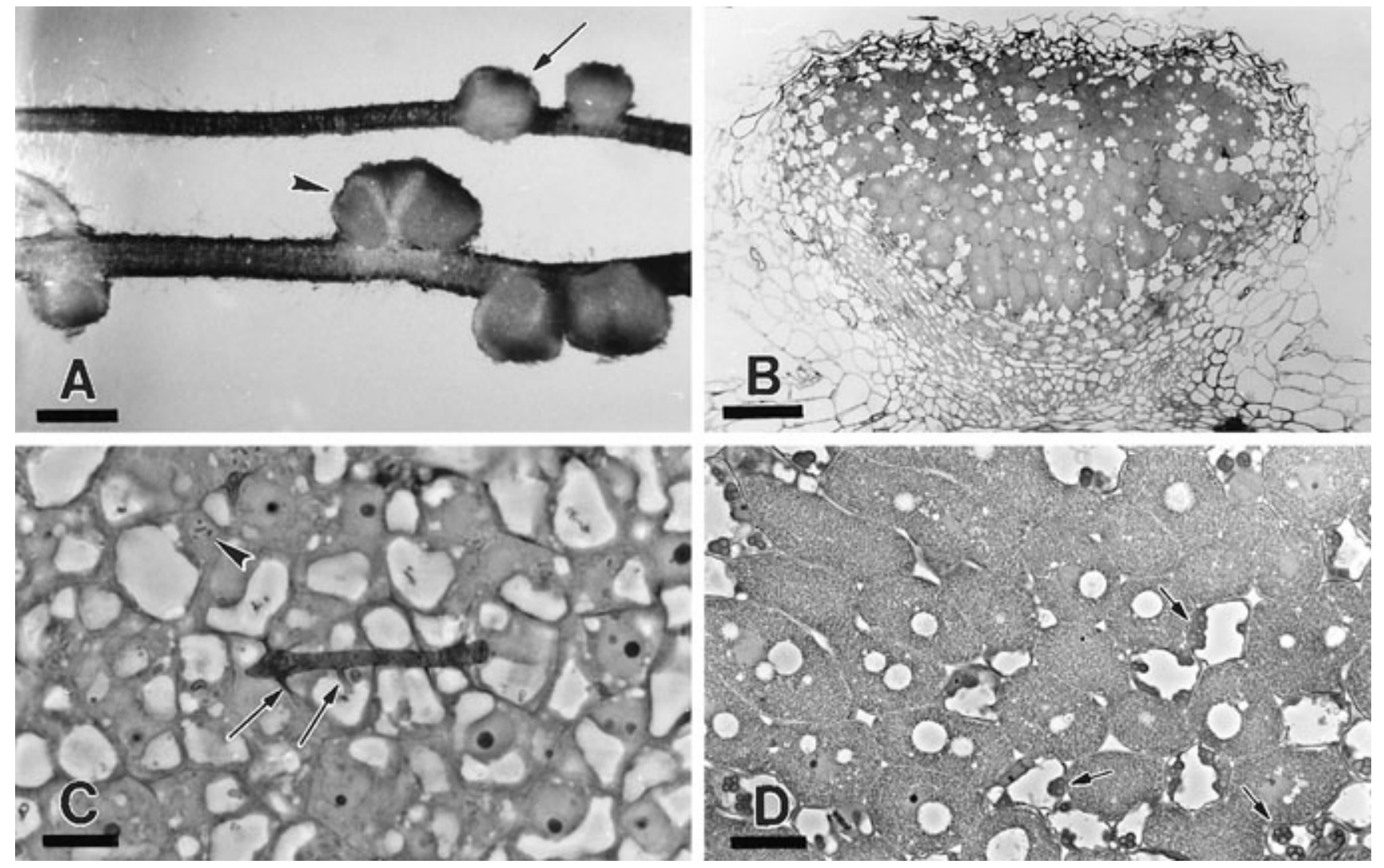

Fig. 3. Root nodules of Lotus japonicus induced by Mesorhizobium loti strain NZP2235. A, Stereomicrograph showing typical spherical nodule (arrow) and less common multi-lobed nodule (arrowhead). B-D, Brightfield micrographs of semithin nodule sections. B, Longitudinal histology of a lobed nodule containing a large, central, infected zone surrounded by an uninfected nodule cortex. C, A wide infection thread spreading between and inside host cells, with thinner lateral branches of the infection thread (arrows) and the bacterial endosymbionts already released into a neighboring host cell (arrowhead). D, A portion of the central zone of a mature nodule, with numerous infected host cells packed with bacterial endosymbionts and lessfrequent, uninfected host cells containing prominent intracellular starch granules (short arrows). Bar, $150 \mu \mathrm{m}(\mathbf{A}), 100 \mu \mathrm{m}(\mathbf{B})$, and $25 \mu \mathrm{m}(\mathbf{C}$ and $\mathbf{D})$.

Fig. 2. Brightfield micrographs of Lotus japonicus roots cleared with hypochlorite solution and stained with methylene blue to reveal the root cortex. A, Normal histology of the root cortex containing three to four layers of cylindrical cells. B-F, Various developmental stages of nodule formation distinguished by extent of Mesorhizobium loti-induced cortical cell divisions. B, An early stage in which anticlinal cell divisions are restricted to a localized area of outer cortex (arrows). C, More anticlinal cortical cell divisions in a localized area containing several layers of the cortex (arrows). D, Clearly defined meristem consisting of the nodule primordium that caused the overlying root epidermis to bulge locally. E, Splitting of the overlying epidermis (arrow) as the young nodule emerged. F, A fully emerged nodule (n). Bar, $70 \mu \mathrm{m}(\mathbf{A}-\mathbf{D})$ and $100 \mu \mathrm{m}(\mathbf{E}$ and $\mathbf{F})$. 
containing peripheral vascular elements and lacking a discrete apical meristem (data not shown). Lobed nodules were found to have a similar histology, including a central, radiating, multilobed, infected zone (Fig. 3B). Examination of young nodules by brightfield microscopy revealed the presence of thick, prominent infection threads that spread between and inside host cells and contained multiple, thinner, lateral branches, as well as early indications of host cell invasion by a few bacterial endosymbionts (Fig. 3C).

In mature nodules, the central zone was primarily found to contain infected host cells, packed with bacterial endosymbionts and featuring a central vacuole. In addition, uninfected host cells, with prominent intracellular starch granules, and uninvaded intercellular spaces could be observed (Fig. 3D). Image analysis of various sections of the central fixation zone showed that the proportional areas occupied by infected host cells, uninfected host cells, and intercellular spaces were 77, 21, and $2 \%$, respectively. These proportional areas are quite similar to the corresponding areas of 80,18 , and $2 \%$ found in mature, effective, indeterminate, alfalfa nodules (Velazquez et al. 1995).

Transmission electron microscopy revealed additional ultrastructural details of the infection process, including infection thread dissemination, bacterial release (Bar), and development of endosymbiotic bacteroids (Bad). Intracellular infection threads were shown to be tubular structures in both crosssectional and longitudinal analyses (Fig. 4A and B). The typical ultrastructure of a $L$. japonicus intracellular infection thread within nodules was found to consist of a multilayered fibrillar wall (139 $\pm 25 \mathrm{~nm}$ thick; Fig. 4A), an overlying enclosure membrane continuous with the cytoplasmic membrane of the infected host cell (Fig. 4B), and a lumen occupying approximately $68 \%$ of the cross-sectional area $\left(2.16 \pm 0.2 \mu \mathrm{m}^{2}\right)$ containing vegetative bacteria embedded in an amorphous matrix. Unlike many legumes, L. japonicus was found to contain infection threads that were often very wide in crosssection, capable of accommodating several vegetative bacteria side by side (Fig. 4A and D). Examination of near-longitudinal sections of infection threads illustrated the release of vegetative bacteria from the tips of narrow infection threads (Fig. 4B and C), as well as from the sides of wider infection threads (Fig. 4D). In both cases, a very localized zone of the infection thread wall was found to be eroded, allowing protrusion of a wall-less, membrane-enclosed, infection droplet, which contained the amorphous matrix of the infection thread lumen. Individual bacterial cells were found to migrate from within the infection thread to the infection droplet, and from there appeared to be released singly from the infection droplet into the cytosol of the host cell, enclosed within their own peribacteroid membrane (Fig. 4C and D). Following endocytosis, some of the membrane-enclosed, endosymbiotic bacteria were found to undergo cell division by binary fission, as evi- denced by a constriction ring approximately equidistant from both cell poles (Fig. 4C). Symbiosomes were found to contain endosymbiotic bacteria ranging in numbers from 1 to 4 (Fig. $4 \mathrm{E})$, with an average of $1.2 \pm 0.5$ per symbiosome $(\mathrm{n}=340)$. In wild-type $L$. japonicus nodules, only a subtle morphological transition from the vegetative state to the bacteroid state could be observed (Fig. 4). Bacteroids typically retained the same straight rod shape as vegetative cells within the nodule. Only rarely, branched or pleomorphic-shaped bacteroids of $M$. loti were observed under these conditions (data not shown). Computer-assisted stereological image analysis of 34 vegetative and 34 bacteroid cells indicated that this morphological transition involved a slight increase in cell length $(1.48 \rightarrow$ $1.78 \mu \mathrm{m})$, no significant change in cell width $(0.60 \rightarrow 0.62$ $\mu \mathrm{m})$, and a corresponding slight (1.3-fold) increase in cell volume $\left(0.42 \rightarrow 0.56 \mu \mathrm{m}^{3}, t\right.$ value $=3.903$ with $\left.66 \mathrm{df}\right)$. Also, the cytoplasm of endosymbiotic bacteroids was found to be more electron-dense and to contain more numerous electron-lucent granules when compared with vegetative bacteria within nodule host cells. A longitudinal section of a typical $M$. loti bacteroid within a symbiosome of a $L$. japonicus nodule cell is shown in Figure 4F.

\section{Isolation of $\boldsymbol{L}$. japonicus symbiotic mutants.}

Of 5,000 L. japonicus seeds treated with $0.6 \%$ EMS for $3 \mathrm{~h}$, 3,000 mature $\mathbf{M}_{1}$ plants were obtained. In addition, a small proportion of L. japonicus seeds (about 500 seeds) treated with 0.4 or $1.0 \% \mathrm{vol} / \mathrm{vol}$ EMS for 3 and $1 \mathrm{~h}$, respectively, were included in the experiment.

Twenty-five hundred of the $\mathrm{M}_{1}$ plants obtained were found to be fertile and to produce $\mathrm{M}_{2}$ families that were screened for symbiotic variants. Approximately $30,000 \mathrm{M}_{2}$ plants were analyzed. Several classes of developmental mutants were observed among the $\mathrm{M}_{2}$ plants, including leaf/stem deformation mutants, dwarflike variants, sterile plants, and infrequent chlorophyll-deficient mutants (data not shown). Twenty stable L. japonicus symbiotic mutants were obtained (Table 1), including a plant variant (LjEMS40) exhibiting a significantly altered root morphology (excess lateral roots formation), in addition to a non-nodulating $\left(\mathrm{Nod}^{-}\right)$symbiotic phenotype.

The L. japonicus mutant lines isolated were given an LjEMS designation, followed by a number corresponding to the original designation of the individual $\mathrm{M}_{2}$ pools (see Materials and Methods). When appropriate, the corresponding mutant alleles were given a genetic designation analogous to the nomenclature used for symbiotic (sym) mutants in pea (see Weeden et al. 1990). The prefix "Lj”'(for Lotus japonicus) was combined with the sym designation (Ljsym), to denote the plant species from which the particular symbiosis-related allele was derived (Table 1). Since L. japonicus symbiotic mutants are being generated in other laboratories, and the first set

Fig. 4. Transmission electron micrographs of Lotus japonicus nodule invasion by Mesorhizobium loti strain NZP2235. A, A cross-section and (B) longitudinal section of tubular, infection threads containing bacteria (b) within the lumen, a multi-layered fibrillar wall (arrows), and enclosed within a membrane that is continuous with the cytoplasmic membrane of the infected host cell (arrowheads). B-D, Wall has eroded at tip of infection threads in B and $\mathbf{C}$, and at the side of a wider infection thread in $\mathbf{D}$ (arrow). C-D, Individual bacteria (b) have migrated into the infection droplet, and appear to have been released singly into the host cell cytosol while enclosed within a peribacteroid membrane. An endosymbiotic bacterium with a central constriction ring (arrowhead) indicative of binary fission is shown in C. E, Portion of an infected host cell containing several symbiosomes with one to four endosymbiotic bacteria. F, Higher magnification of a portion of an infected host cell, showing longitudinal sections of endosymbiotic bacterioids of $M$. lot $i$ surrounded by peribacteroid membranes. Bar, $350 \mathrm{~nm}(\mathbf{A}$ and $\mathbf{F}), 900 \mathrm{~nm}(\mathbf{B}$ and $\mathbf{C})$, and $1 \mu \mathrm{m}(\mathbf{D}$ and $\mathbf{E})$. 
of 20 mutants will be described by J. Stougaard and colleagues (Aarhus University, Denmark), our numerical designation commences with number 21 (Ljsym 21).
The phenotypes of the symbiotic mutants obtained were grouped into six distinct classes (Table 1): (i) absence of nodulation with a wild-type root phenotype [ $\left.\mathrm{Nod}^{-}\right]$; (ii) occa-

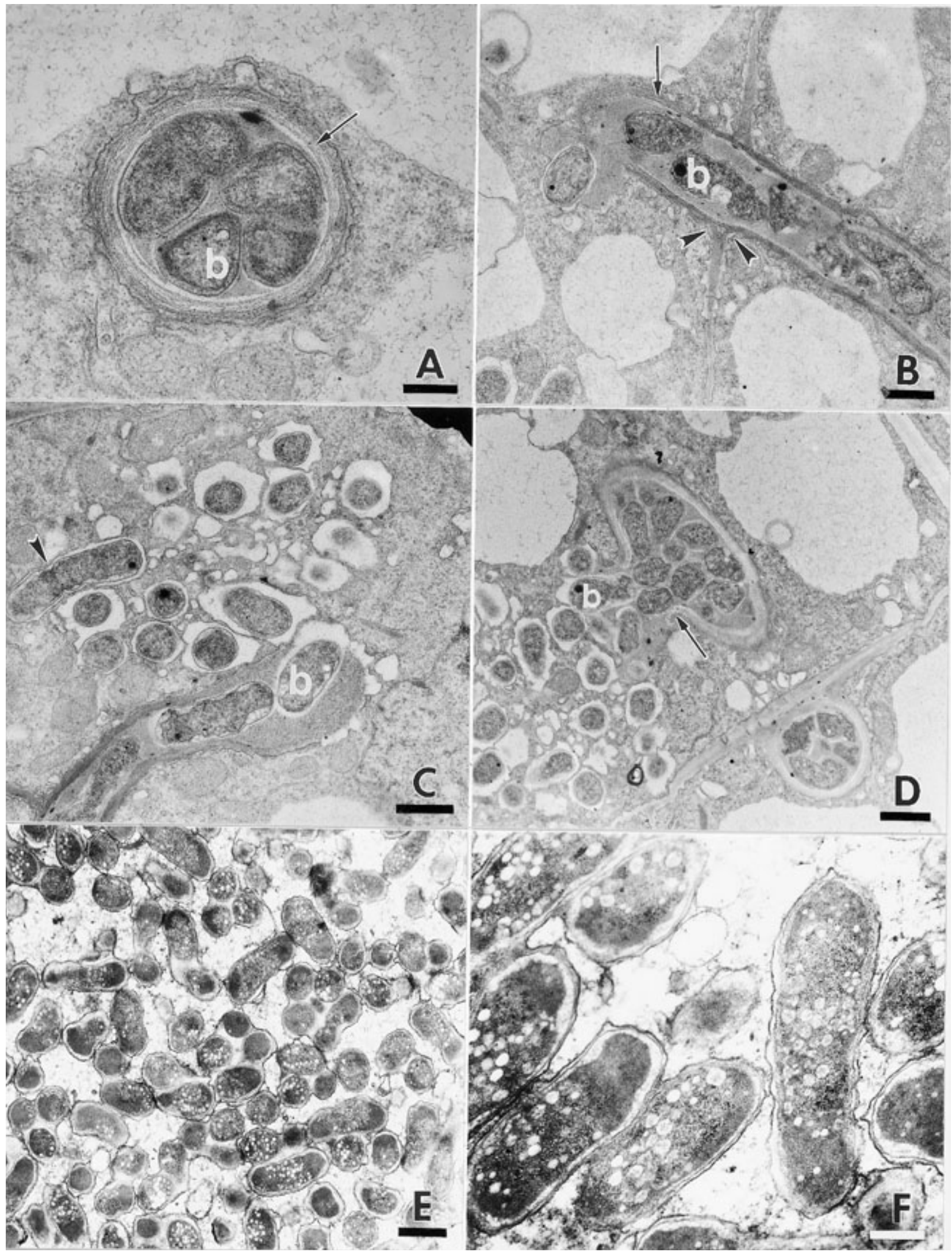


sional small, white, nodulelike structures on the root $\left[\mathrm{Nod}^{-*}\right]$; (iii) absence of nodulation with a changed root morphology [Nod ${ }^{-} \mathrm{Brl}$; (Bushy root lotus)]; (iv) white nodulelike structures $\left[\mathrm{Nod}^{+}, \mathrm{Fix}^{-}\right]$; (v) mixed white and wild-type nodules $\left[\mathrm{Nod}^{+}\right.$ $\left.\mathrm{Fix}^{-/+}\right]$; and (vi) excessive nodule numbers $\left[\mathrm{Nod}^{++}\right]$. Symbiotic phenotypes of selected $L$. japonicus mutants belonging to classes 1, 3, 4, and 6 are shown in Figure 5.

\section{Analysis of the $L$. japonicus Nod' $^{-}$mutants.}

Three distinct classes of $L$. japonicus nodulation-deficient mutants were identified among the symbiotic variants. The first class comprised 11 independent isolates (derived from different $\mathrm{M}_{2}$ pools) and was found to represent at least $8 \mathrm{com}$ plementation groups (Table 1). When these mutant lines were grown in the presence of $M$. loti strain NZP2235 in the ab-

Table 1. Lotus japonicus symbiotic mutants

\begin{tabular}{|c|c|c|c|c|}
\hline $\begin{array}{l}\text { Mutant } \\
\text { lines }\end{array}$ & $\begin{array}{c}\text { Phenotypes } \\
\mathbf{M}_{4}\end{array}$ & $\begin{array}{l}\text { Genetic control } \\
\quad(P>0.05)\end{array}$ & $\begin{array}{l}\text { Comp. } \\
\text { groups }\end{array}$ & $\begin{array}{c}\text { Allele } \\
\text { designation }\end{array}$ \\
\hline \multicolumn{5}{|l|}{ Class 1} \\
\hline LjEMS34 & $\mathrm{Nod}^{-}$ & $\begin{array}{l}\text { Monogenic recessive } \\
\mathrm{F}_{2} 150: 51\left(\chi^{2}=0.014\right)\end{array}$ & a & Ljsym 21-1 \\
\hline LjEMS46 & $\mathrm{Nod}^{-}$ & $\begin{array}{l}\text { Monogenic recessive } \\
\mathrm{F}_{2} 57: 18\left(\chi^{2}=0.04\right)\end{array}$ & $\mathrm{b}$ & Ljsym 22-1 \\
\hline LjEMS61 & $\mathrm{Nod}^{-}$ & $\begin{array}{l}\text { Monogenic recessive } \\
\mathrm{F}_{2} 35: 10\left(\chi^{2}=0.184\right)\end{array}$ & $\mathrm{a}$ & Ljsym 21-2 \\
\hline LjEMS70 & $\mathrm{Nod}^{-}$ & $\begin{array}{l}\text { Monogenic recessive } \\
\mathrm{F}_{2} 58: 20\left(\chi^{2}=0.016\right)\end{array}$ & $\mathrm{c}$ & Ljsym 23-1 \\
\hline LjEMS76 & $\mathrm{Nod}^{-}$ & $\begin{array}{l}\text { Monogenic recessive } \\
F_{2} 92: 36\left(\chi^{2}=0.666\right)\end{array}$ & d & Ljsym 24 \\
\hline LjEMS167 & $\mathrm{Nod}^{-}$ & $\begin{array}{l}\text { Monogenic recessive } \\
\mathrm{F}_{2} 72: 30\left(\chi^{2}=1.058\right)\end{array}$ & $\mathrm{c}$ & Ljsym 23-2 \\
\hline LjEMS223 & $\mathrm{Nod}^{-}$ & $\begin{array}{c}\text { Monogenic recessive } \\
\mathrm{F}_{2} 123: 35\left(\chi^{2}=0.683\right)\end{array}$ & $\mathrm{e}$ & Ljsym 25 \\
\hline LjEMS237 & $\mathrm{Nod}^{-}$ & $\mathrm{ND}^{\mathrm{z}}$ & $\mathrm{ND}^{\mathrm{z}}$ & - \\
\hline LjEMS247 & $\mathrm{Nod}^{-}$ & $\begin{array}{c}\text { Monogenic recessive } \\
\mathrm{F}_{2} 162: 47\left(\chi^{2}=0.697\right)\end{array}$ & $\mathrm{f}$ & Ljsym 26 \\
\hline \multicolumn{5}{|l|}{ Class 2} \\
\hline LjEMS81 & $\mathrm{Nod}^{-*}$ & $\begin{array}{c}\text { Monogenic recessive } \\
\mathrm{F}_{2} 56: 20\left(\chi^{2}=0.069\right)\end{array}$ & $\mathrm{g}$ & Ljsym27 \\
\hline LjEMS236 & $\mathrm{Nod}^{-*}$ & $\begin{array}{l}\text { Monogenic recessive } \\
\mathrm{F}_{2} 103: 45\left(\chi^{2}=2.3\right)\end{array}$ & $\mathrm{h}$ & Ljsym28 \\
\hline \multicolumn{5}{|l|}{ Class 3} \\
\hline LjEMS40 & Brl, Nod $^{-}$ & $\begin{array}{c}\text { Digenic } \\
\mathrm{F}_{2} 109: 37: 28 ; 12\left(\chi^{2}=\right. \\
1.678)\end{array}$ & - & $\begin{array}{l}\text { Ljsym22-2 } \\
\text { Ljsym34-2 }\end{array}$ \\
\hline \multicolumn{5}{|l|}{ Class 4} \\
\hline LjEMS45 & $\mathrm{Nod}^{+}, \mathrm{Fix}^{-}$ & $\begin{array}{l}\text { Recessive } \\
\mathrm{F}_{2} 749: 74\end{array}$ & $\mathrm{i}$ & \\
\hline LjEMS88 & $\operatorname{Nod}^{+}, \mathrm{Fix}^{-}$ & $\begin{array}{l}\text { Recessive } \\
\mathrm{F}_{2} 539: 63\end{array}$ & $\mathrm{i}$ & \\
\hline LjEMS217 & $\mathrm{Nod}^{+}, \mathrm{Fix}^{-}$ & $\begin{array}{l}\text { Recessive } \\
\mathrm{F}_{2} 704: 88\end{array}$ & $\mathrm{i}$ & \\
\hline LjEMS126 & $\mathrm{Nod}^{+}, \mathrm{Fix}^{-}$ & $\begin{array}{c}\text { Monogenic recessive } \\
\mathrm{F}_{2} 226: 79\left(\chi^{2}=0.132\right)\end{array}$ & $\mathrm{j}$ & Ljsym30 \\
\hline \multicolumn{5}{|l|}{ Class 5} \\
\hline LjEMS75 & $\mathrm{Nod}^{+}, \mathrm{Fix}^{-/+}$ & $\begin{array}{c}\text { Monogenic recessive } \\
\mathrm{F}_{2} 327: 105\left(\chi^{2}=\right. \\
0.111)\end{array}$ & $\mathrm{k}$ & Ljsym31 \\
\hline LjEMS208 & $\mathrm{Nod}^{+}, \mathrm{Fix}^{-/+}$ & $\begin{array}{l}\text { Monogenic recessive } \\
\mathrm{F}_{2} 38: 14\left(\chi^{2}=0.096\right)\end{array}$ & 1 & Ljsym32 \\
\hline LjEMS79 & $\begin{array}{l}\operatorname{Nod}^{-/+} \\
\mathrm{Fix}^{-/+}\end{array}$ & $\begin{array}{l}\text { Monogenic recessive } \\
\mathrm{F}_{2} 75: 15\left(\chi^{2}=2.4\right)\end{array}$ & $\mathrm{m}$ & Ljsym33 \\
\hline \multicolumn{5}{|l|}{ Class 6} \\
\hline LjEMS102 & $\begin{array}{l}\mathrm{Nod}^{++} \\
\text {Brl, Nts }\end{array}$ & $\begin{array}{c}\text { Monogenic, incom- } \\
\text { plete dominant } \\
\mathrm{F}_{2} 116: 35\left(\chi^{2}=0.266\right)\end{array}$ & $\mathrm{n}$ & Ljsym34-1 \\
\hline
\end{tabular}

${ }^{\mathrm{z}}$ Not determined. sence of combined nitrogen no macroscopically visible nodules were observed on otherwise normal-looking roots $\left(\mathrm{Nod}^{-}\right)$. The second class consisted of lines LjEMS81 and LjEMS236, which occasionally contained a few, very small, white, round, nodulelike structures on their roots (data not shown). We will refer to these two L. japonicus lines as $\mathrm{Nod}^{-*}$ mutants, to reflect their "leaky" nodulation phenotype.

Genetic analysis of the L. japonicus $\mathrm{Nod}^{-}$and $\mathrm{Nod}^{-*}$ plants revealed that the phenotype of all lines, except for LjEMS237, was determined by a monogenic, recessive mutation (Table 1). In the case of LjEMS237, the genetic basis of the observed phenotype could not be determined due to poor growth and significantly reduced fertility.

A third class of $\mathrm{Nod}^{-}$mutants was represented by a single $L$. japonicus line, LjEMS40. This mutant was originally identified as having a bushy root phenotype (Brl), due to an excessive number of lateral roots formed $\left(\mathrm{Nod}^{-}, \mathrm{Brl}\right.$; Table 1 ; Fig. 5A). The overall length of the main root of LjEMS40 plants was found to be diminished, compared with the wild-type "Gifu" parental line (data not shown; see below). When the LjEMS40 line was backcrossed to the parental line Gifu, the $\mathrm{F}_{1}$ hybrid progeny formed wild-type nodules on normallooking roots. The $\mathrm{F}_{2}$ progeny, however, displayed four different phenotypes: (i) wild type; (ii) $\mathrm{Nod}^{-}$(wild-type root morphology); (iii) $\mathrm{Nod}^{++}$; and (iv) $\mathrm{Nod}^{-} \mathrm{Brl}$, segregating at a ratio of 9:3:3:1 (Table 1). The latter result suggests the presence of two unlinked mutations in the LjEMS40 line, including one responsible for the non-nodulating $\left(\mathrm{Nod}^{-}\right)$phenotype, and the second one conferring the hypernodulating Nod $^{++}$phenotype.

When analyzed further, the hypernodulating phenotype was found to be linked to the bushy root (Brl) phenotype, since all $\mathrm{Nod}^{++}$plants segregating from the LjEMS40 line displayed a bushy root phenotype when grown in the absence of rhizobia (data not shown). In contrast, the non-nodulating phenotype of the LjEMS40 line was found to be associated with a wild-type root morphology (Table 1). Using crosses, the $\mathrm{Nod}^{-}$mutation of the LjEMS40 line was found to be allelic to the Ljsym22 locus (LjEMS46 line; Table 1). The $\mathrm{F}_{1}$ progeny of plants derived from the genetic cross between lines LjEMS40 and LjEMS46 was found to be $\mathrm{Nod}^{-}$and to have a wild-type root phenotype. $\mathrm{F}_{2}$ progeny of this cross displayed a $\mathrm{Nod}^{-}$phenotype, segregating wild-type and bushy root $(\mathrm{Brl})$ phenotypes at a $3: 1$ ratio (75 wild-type : 28 bushy root; $\chi^{2}=0.262 ; P>$ $0.05)$. The underlying alleles were designated Ljsym22-1 and Ljsym22-2, respectively (Table 1). The mutation responsible for the hypernodulating $\mathrm{Nod}^{++}$phenotype of the LjEMS40 line was found to be allelic to Ljsym34 (see below). Therefore, the corresponding gene was named Ljsym 34-2. The root and symbiotic phenotypes of line LjEMS40 could be reconstituted by crossing lines LjEMS46 and LjEMS102. In the $\mathrm{F}_{2}$ generation, 1 out of 16 plants was found to display the same $\mathrm{Nod}^{-}$ Brl phenotype as the LjEMS40 line (data not shown).

Analysis of $L$. japonicus $\mathrm{Nod}^{+} \mathrm{Fix}^{-}$and $\mathrm{Nod}^{+} \mathrm{Fix}^{-/+}$mutants.

Seven independent $\mathrm{Nod}^{+} / \mathrm{Fix}^{-}$(class 4), and $\mathrm{Nod}^{+} / \mathrm{Fix}^{-/+}$ (class 5) lines, representing 5 complementation groups, were identified (Table 1). These plants formed visible nodules upon inoculation with rhizobia, but their size, number, and distribution varied significantly.

The class 4 mutant line LjEMS126 formed relatively infrequent, small, white, nodulelike structures on the roots, when 


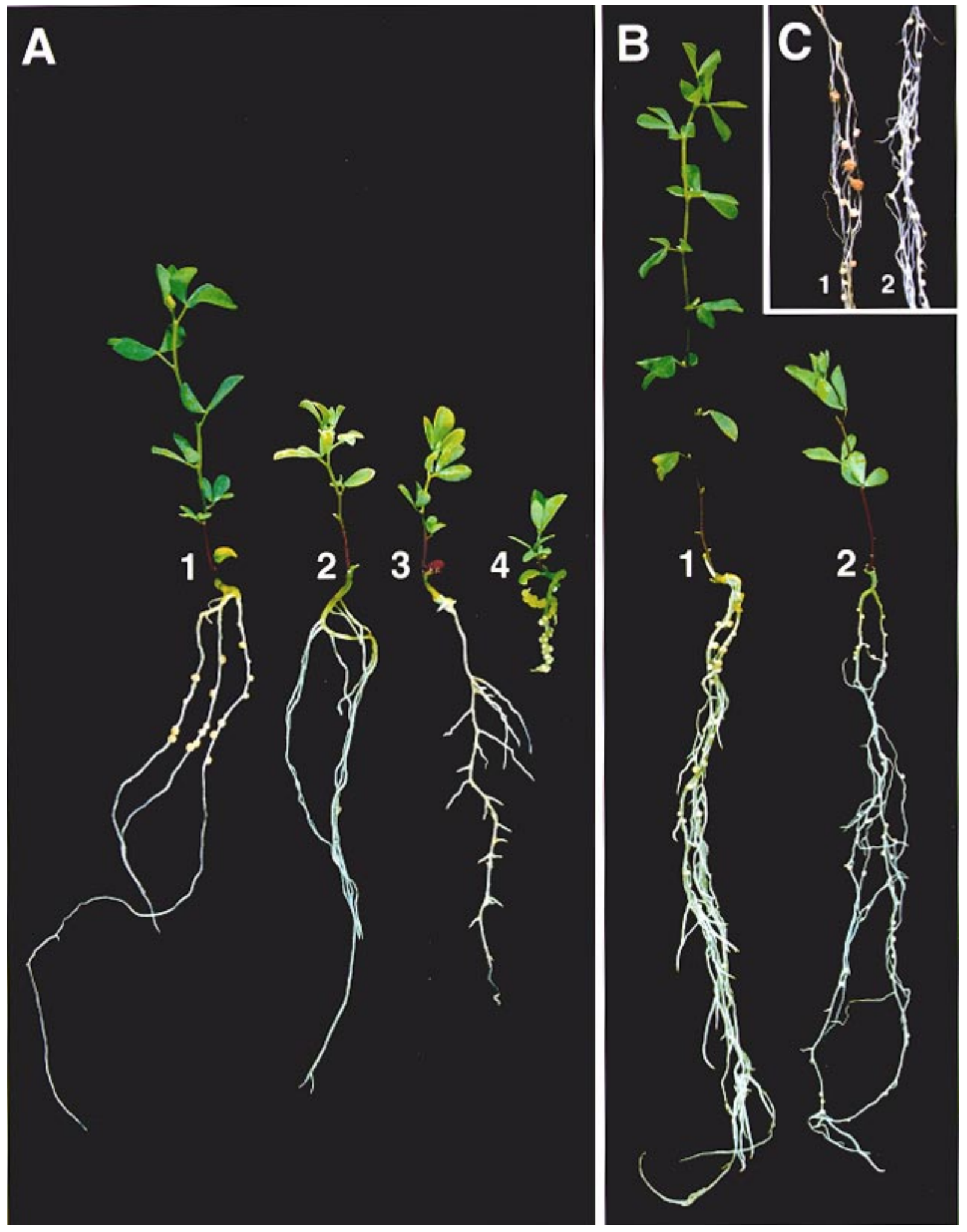

Fig. 5. Phenotypes of wild-type and mutant Lotus japonicus "Gifu" plants inoculated with Mesorhizobium loti NZP2235 and grown in the presence of $0.5 \mathrm{mM}$ combined nitrogen. A, Twenty-one days after inoculation; (1) wild type; (2) LjEMS46 (Nod'; class1); (3) LjEMS40 (Nod ${ }^{-}$, Brl; class 3); (4) LjEMS102 ( Nod $^{++}$, Brl, Nts; class 6). B, Thirty-five days after inoculation; (1) wild type; (2) LjEMS75 ( Nod $^{+}$, Fix ${ }^{-/+}$; class 5). C, Close-up of root sections shown in $\mathbf{B}$. 
analyzed 21 and 35 days after inoculation. The nitrogenase activity, as measured with an acetylene reduction assay, could not be detected in these nodules (data not shown).

Class 4 mutant lines LjEMS45, LjEMS88, and LjEMS217 were extensively nodulated on both the upper and lower portions of the roots. As in the case of the LjEMS126 line, no nitrogenase activity could be detected in nodules formed on the LjEMS45, LjEMS88, and LjEMS217 lines, 21 or 35 days after inoculation. These three class 4 lines showed a stable inheritance pattern with regard to their symbiotic phenotype for at least three generations. When backcrossed to the parental line Gifu, wild-type plants could be observed in the $\mathrm{F}_{1}$ generation, indicating that the underlying mutations are recessive. However, in the $F_{2}$ generation, a $10: 1$ ratio of normal versus mutant plants was found (Table 1). The reason for this unusual segregation ratio is unclear; however, it is possible that the reduced pollen viability of the mutant genotype, or segregation distortion for two linked loci, caused the aberrant segregation ratio observed. The $\mathrm{F}_{1}$ plants from crosses between these three lines showed a similar mutant phenotype, suggesting that the underlying mutations are allelic (Table 1). We have withheld the final designation of these alleles pending further investigation.

Class 5 mutant lines LjEMS75 and LjEMS208 revealed a complex symbiotic phenotype at 35 days after inoculation, including the presence of white nodules, and occasional pink, wild-type-like nodules. The majority of the nodules formed on LjEMS75 roots were well developed but white in appearance (Fig. 5B, C), and only in rare cases could wild-type-like nodules be observed (data not shown). In contrast, LjEMS208 nodules were smaller in size and pink. Despite their ability to produce wild-type-like nodules, plants of these two lines were always stunted and chlorotic. Acetylene reduction assays revealed that the nitrogenase activity in nodules induced on both mutant plant lines was significantly reduced relative to the wild-type Gifu line.

The class 5 line LjEMS79 displayed a symbiotic phenotype that was difficult to interpret. All the plants analyzed were stunted and chlorotic, indicative of a possible impairment in their symbiotic properties. More than $50 \%$ of the plants analyzed showed no visible signs of nodulation, and the rest developed white, nodulelike structures, or one or two big pink nodules per plant. The mutation underlying the phenotype of the LjEMS79 line was found to be recessive and segregated in the $\mathrm{F}_{2}$ generation as a monogenic trait (Table 1).

All the L. japonicus mutant plants described above developed just like the wild-type parental line when grown under nonsymbiotic conditions in the presence of nitrate.

\section{Analysis of the L. japonicus Nod ${ }^{++}$ hypernodulating mutant.}

A single plant in class 6 (LjEMS102; Table 1) was recovered from mutagenized $\mathrm{M}_{2}$ populations. Inoculated plants of LjEMS102 line displayed a hypernodulating phenotype, lacked secondary root formation, and were suppressed in both root and stem growth. Twenty-one days after inoculation, the roots of LjEMS102 plants were found to be covered with nodules and growth of the infected plants was almost completely suppressed (Fig. 5A). The upper portion of the infected plants appeared to be chlorotic, indicative of nitrogen deficiency.

In addition to its Nod $^{++}$phenotype, the class 6 LjEMS102 line displayed an interesting nonsymbiotic phenotype. When grown in the absence of rhizobia and in the presence of a low concentration of $\mathrm{KNO}_{3}(0.5 \mathrm{mM})$, LjEMS102 plants displayed a diminished root length, and a concomitant increase in lateral root formation (Brl), which clearly resembled the root phenotype of LjEMS40 line (Fig. 5A). The overall growth pattern of the uninoculated LjEMS102 plants was found to be similar to that observed for the wild-type Gifu line. The symbiotic (hypernodulation; $\mathrm{Nod}^{++}$) and nonsymbiotic (bushy root; Brl) phenotypes of the LjEMS102 line were found to be due to a monogenic mutation by analyzing the segregation pattern of the $F_{2}$ progeny from a backcross of the LjEMS102 and wildtype Gifu parental lines (Table 1).

When the class 6 LjEMS102 line was crossed with the class 3 line LjEMS40, $F_{1}$ hybrid progeny displayed the hypernodulating phenotype characteristic of both parental lines. The observed lack of complementation of the hypernodulating phenotype and the concomitant complementation of the LjEMS40 non-nodulating phenotype indicate that the mutations underlying the hypernodulation phenotype in both lines are allelic. This assumption was confirmed by analyzing the segregation pattern among the $\mathrm{F}_{2}$ plants of the allelic cross. In the presence of rhizobia, the $\mathrm{Nod}^{++}$and $\mathrm{Nod}^{-} \mathrm{Brl}$ phenotypes segregated according to a monohybrid 3:1 ratio (70 hypernodulating : 20 non-nodulating, bushy root; $\left.\chi^{2}=0.369 ; P>0.05\right)$. However, in the absence of bacteria, all $\mathrm{F}_{2}$ plants analyzed (>100 plants) displayed a bushy root phenotype (Brl). These results show that the symbiotic (hypernodulating) and nonsymbiotic (bushy root) phenotypes of the independently isolated class 6 LjEMS102 and class 3 LjEMS40 lines result from a mutation in a single nuclear gene and suggest an epistatic interaction between nodule formation and non-nodulation (see also Delves et al. 1986).

\section{Nodulin gene expression in selected Nod $^{+} \mathrm{Fix}^{-}$ mutant lines.}

A molecular analysis, using early and late nodulin marker genes, was performed to further characterize the $\mathrm{Nod}^{+} \mathrm{Fix}^{-}$and $\mathrm{Nod}^{+} \mathrm{Fix}^{-/+}$lines. Total RNA isolated from 35-day-old, wildtype nodules induced on the parental line Gifu, and from nodules or nodulelike structures induced on the class 4 and 5 lines LjEMS45, LjEMS88; LjEMS217, LjEMS126, and LjEMS208, as well as the non-nodulating class 1 line LjEMS46, was hybridized with a selection of nodule-specific gene probes. The $L j N 77$ probe, corresponding to one of the $L$. japonicus leghemoglobin genes (Szczyglowski et al. 1997), strongly hybridized to RNA from the wild-type and class 5 LjEMS208 mutant line (Fig. 6). In contrast, the level of leghemoglobin mRNA in the class 4 mutant lines LjEMS45, LjEMS88, and LjEMS217 was approximately 50-fold reduced, compared with the wild-type line, and was not detectable in the class 4 LjEMS126 and the class 1 non-nodulating LjEMS46 lines or in control uninfected root RNA (Fig. 6).

The level of LjENOD2 mRNA was found to be similar in the wild-type, class 4 LjEMS45, LjEMS88, and LjEMS217, and class 5 LjEMS208 mutant lines. Wild-type uninfected control roots showed a background level of LjENOD2 mRNA, whereas no signal could be found in the LjEMS126 line and in roots of the non-nodulating line LjEMS46 (Fig. 6). When the L. japonicus LjN13 EST, corresponding to the early nodulin ENOD40 (Szczyglowski et al. 1997), was used as a probe, a 
significantly different pattern of gene expression was observed. A strong hybridization signal was detected in nodules induced on wild-type and class 5 LjEMS208 mutant plants. A very low background level of ENOD40 gene expression was detected in wild-type uninfected roots, in the class 4 LjEMS45, LjEMS88, and LjEMS217 lines and class 1 LjEMS46 line, whereas no hybridization signal could be found in the class $4 \mathrm{LjEMS126}$ line (Fig. 6).

\section{DISCUSSION}

In this paper we describe a thorough microscopical study of root infection and nodule ontogeny in wild-type $L$. japonicus roots in order to provide a reference point of detailed morphological features for the analysis of symbiotic mutants. This analysis revealed that root nodule development in $L$. japonicus is clearly of the determinant type, in that activation of the first foci of cell divisions occurs within the outer cortex, and spherical and lobed nodules develop without a single, localized, persistent meristem. In addition, our study revealed several peculiar and distinct morphological features of infection and nodule ontogeny that will help to identify discrete blocks in developmental stage(s) of symbiotically defective $L$. japonicus mutants. First, primary host infection in wild-type $L$. japonicus plants occurs more frequently in elongated root hairs with the development of infection threads at the tip of "shepherd's-crook" curvatures, than within short, deformed root hairs, as occurs predominantly in soybean. This implies that root-hair infectibility in L. japonicus persists throughout elongation development (as in white clover) rather than just during a very brief period immediately following committed epidermal differentiation. Second, the outer surface of the infection thread within successfully infected root hairs of $L$. japonicus is commonly rough with papillae rather than smooth, indicating that development of the infection thread wall during primary infection differs from successful root-hair infections found in other legumes (Dazzo and Petersen 1988; Turgeon and Bauer 1985; Vasse et al. 1993). Third, the infection threads within $L$. japonicus nodules can be unusually wide with a lumen large enough to enclose several vegetative bacteria side by side. These wide infection threads develop several side branches having a smaller normal width sufficient only for a single row alignment of bacteria. Fourth, two types of bacterial release structures are found that involve localized dissolution of the infection thread wall and formation of the infection droplet. One occurs at the tip of the thin infection thread, as commonly found in other legumes, and the other develops along the side of the very wide infection thread. Fifth, M. loti undergoes only marginal morphological transitions during the differentiation of vegetative bacteria into bacteroids within L. japonicus nodules. This transition involves only a slight enlargement in cell volume (quite unlike most other legumes, where the enlargement is profound) and intracellular accumulation of numerous, small, electron-lucent granules, rather than just a few large ones. Sixth, the typical symbiosome in wild-type L. japonicus nodules contains predominantly one to two $M$. loti bacteroids closely surrounded by the peribacteroid membrane, with little if any indication of being embedded in an extensive symbiosome matrix of fibrillar polymeric material, as occurs in determinant nodules of

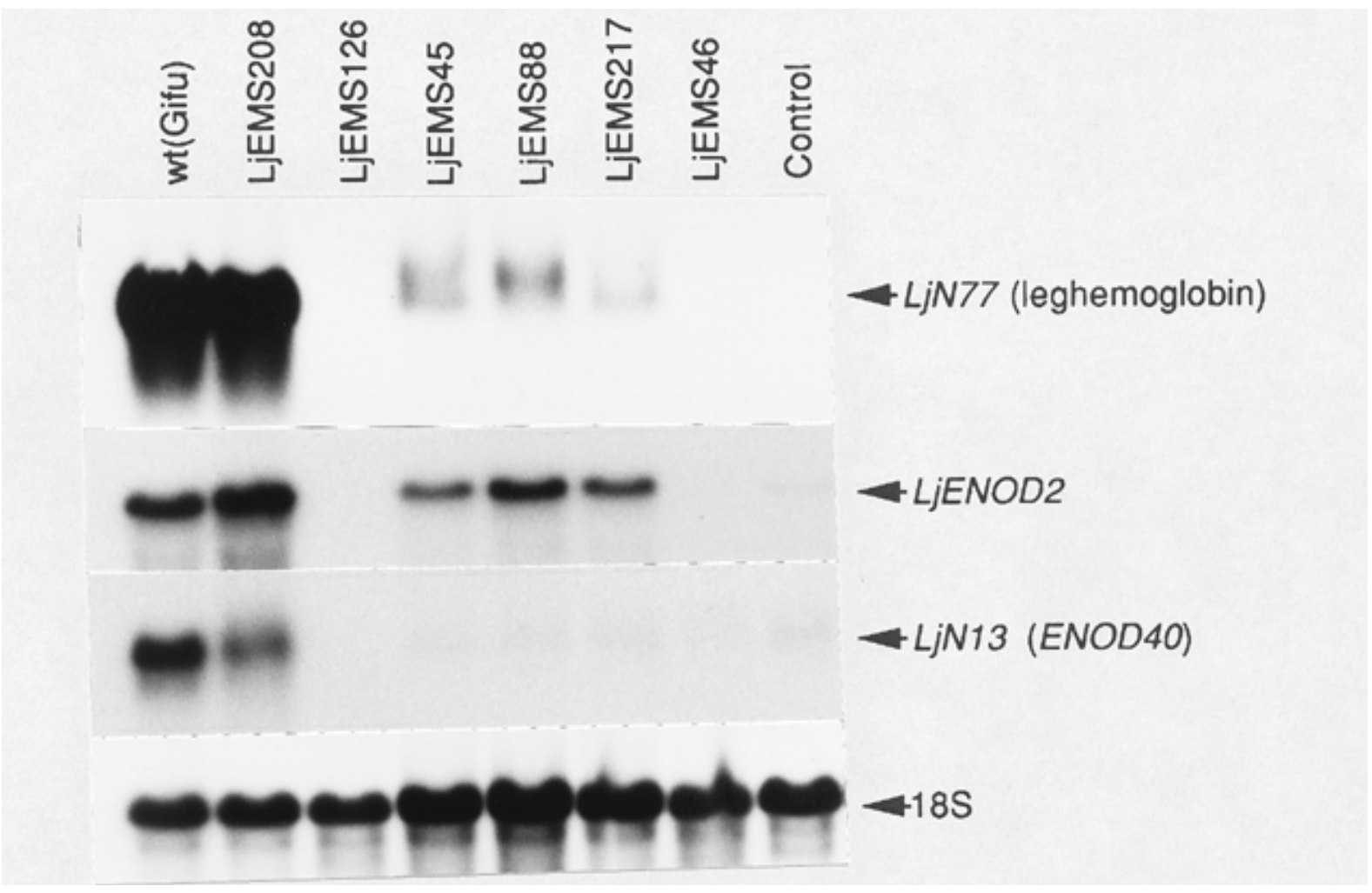

Fig. 6. Comparision of mRNA levels of Lotus japonicus lb, ENOD2, and ENOD40 genes: in wild-type nodules (lane 1); in nodule and nodule-like structures of the mutants LjEMS208 (lane 2), LjEMS126 (lane 3), LjEMS45 (lane 4), LjEMS88 (lane 5), LjEMS217 (lane 6), LjEMS46 (lane 7); and in control uninoculated wild type roots (lane 8). 
other legumes (Streeter and Salminen 1993; Subba-Rao et al. 1995).

In addition to the detailed morphological analysis of wildtype nodule organogenesis, we have also described here the isolation and initial characterization of 20 stable, EMSinduced symbiotic mutants of the legume L. japonicus. L. japonicus was chosen for this genetic analysis because of its relatively small genome size, diploid nature, low chromosome number $(\mathrm{n}=6)$, short generation time (approximately 3 months), large self-fertile flowers, large seed number, and transformability, making it an excellent model system for the genetic and molecular studies of determinate nodule formation (Handberg and Stougaard 1992; Jiang and Gresshoff 1993, 1997; Cook et al. 1997; de Bruijn et al. 1998).

We were able to divide the $20 \mathrm{~L}$. japonicus mutants into at least 14 complementation groups. Different classes of $L$. japonicus symbiotic variants were identified, ranging from plants that did not display macroscopically visible signs of nodulation (non-nodulating or $\mathrm{Nod}^{-}$mutants), to variants forming white, mostly ineffective nodules $\left(\mathrm{Nod}^{+} \mathrm{Fix}^{-/+}\right)$, or excessive numbers of nodules $\left(\mathrm{Nod}^{++}\right)$. Moreover, of $20 \mathrm{~L}$. japonicus root-nodule mutants described here, at least 7 mutants (LjEMS34, 46, 61, 70, 76, 167, 126), representing 5 different complementation groups, also appear to form a defective symbiosis with mycorrhizal fungi (M. Parniske, F. J. de Bruijn, and K. Szczyglowski, unpublished results). Analogous categories of symbiotic mutants have been reported for other legume species (see Caetano-Anolles and Gresshoff 1991b; Harrison 1997). Recently, two $\mathrm{Nod}^{+} \mathrm{Fix}^{-}$ mutants have been described in L. japonicus as well (Imaizumi-Anraku et al. 1997).

A mutation affecting L. japonicus root development was also identified in our genetic screen. Both LjEMS102 and LjEMS40 mutant lines, when grown in the presence of combined nitrogen and absence of rhizobia, show a modified pattern of root development, characterized by an overall shortening of root length and abundant lateral root formation. The aerial portions of the mutant plants appeared to be normal. The mutations underlying the altered root development phenotype in both these independently isolated $L$. japonicus lines were found to be allelic, and the corresponding alleles were designated Ljsym34-1 and Ljsym34-2, respectively. Interestingly, the presence of the same alleles was found to confer a hypernodulation response, when plants were grown in the presence of the wild-type $M$. loti strain NZP2235 (de Bruijn et al. 1998; Szczyglowski et al. 1998). The latter phenomenon was characterized by the presence of nodule structures covering almost the entire root length $\left(\mathrm{Nod}^{++}\right)$, with a concomitant inhibition of both root and stem growth and a rapid deterioration of overall plant vitality (Fig. 5; Szczyglowski et al. 1998). The drastically altered root morphology as well as the striking hypernodulation response upon infection appear to distinguish this line of mutant from previously described hypernodulating variants of pea, soybean, and other legume species (Jacobsen and Feenstra 1984; Day et al. 1986; Novak et al. 1997; Penmetsa and Cook 1997). Therefore, alleles Ljsym34-1 and Ljsym34-2 may define a novel locus involved in symbiotic interaction. We are currently analyzing both root and symbiotic properties of the L. japonicus LjEMS102 line in greater detail. The analysis of this mutant line should allow us to address a long-standing question regarding the relationship between the mechanism(s) controlling nodulation and primary root/1 ateral root development (Hirsch and LaRue 1997).

Since at least 8 different genes conferring a non-nodulating phenotype $\left(\mathrm{Nod}^{-}\right)$were identified, further detailed evaluation of their symbiotic properties, using combinations of molecular, genetic, and microscopical tools, should help to define the specific stages at which the individual mutants are arrested. The detailed microscopical analysis of the wild-type nodule organogenesis described here provides the necessary framework for such an evaluation. Our preliminary molecular characterization of selected L. japonicus mutants, forming mostly ineffective nodules, has already distinguished at least three different categories of mutants, based on the observed levels of selected nodulin gene mRNAs. Interestingly, this analysis also revealed an association of L. japonicus LjN13 (ENOD40 homologue; Szczyglowski et al. 1997) gene expression with relatively late developmental events in nodule organogenesis. It is important to note here that the presence of two ENOD40 genes, which are not coordinately expressed during L. japonicus nodule development, has been reported recently. (Flematakis et al. 1998). The availability of an extensive collection of L. japonicus nodule-associated ESTs (Szczyglowski et al. 1997; Kapranov et al. 1997) will further facilitate the detailed molecular analysis of the symbiotic mutants. Moreover, integration of the symbiosis-associated loci identified here into the rapidly developing genetic and physical map of this model legume (see Jiang and Gresshoff 1997) should provide landmarks for future efforts at map-based cloning of genes important for the root-nodule symbiosis.

\section{MATERIALS AND METHODS}

Plant material and Rhizobium inoculation experiments.

Lotus japonicus ecotype B-129-S9 Gifu (kindly provided by Jens Stougaard, Aarhus, Denmark) was used as the parental line for mutagenesis treatment and as a wild-type control line for other experiments. The $M$. loti wild-type strain NZP2235 was used in all nodulation experiments, as described previously (Szczyglowski et al. 1997).

For microscopical studies, L. japonicus wild-type seeds were scarified and surface sterilized as described (Handberg and Stougaard 1992). Sterile seeds were germinated on B and D nutrient medium (Broughton and Dilworth 1971) solidified with $0.8 \%$ Bacto agar, under $24 \mathrm{~h}$ constant light at $23^{\circ} \mathrm{C}$ for 8 days. Under these conditions, seeds germinated within 2 to 3 days and roots were approximately $12 \mathrm{~mm}$ long by 8 days. Axenic seedlings were transferred to a nylon "pillow system" (see below) and grown in a growth chamber (18 $\mathrm{h}$ photoperiod, $246 \mu \mathrm{E} \mathrm{s} \mathrm{s}^{-1}, 22^{\circ} \mathrm{C} / 18^{\circ} \mathrm{C}$ day/night temperature, and $70 \%$ relative humidity). A single "pillow system" was composed of 9 pillow-shaped nylon bags, filled with a 6:1 vermiculite/sand mixture and placed side by side in a narrow flat tray. Eight-day-old L. japonicus seedlings were placed in-between individual pillows (approximately 5 plants in a single row), and the tray was covered with Saran Wrap and 2 layers of cheesecloth. The pillows were soaked with $\mathrm{B}$ and $\mathrm{D}$ nutrient solution containing $0.5 \mathrm{mM} \mathrm{KNO}_{3}$, before planting, and again 6 and 7 days later. At that time both the cheesecloth and the Saran Wrap were completely removed. 


\section{Microscopy of symbiotic development.}

Roots of wild-type L. japonicus were inoculated with $M$. loti strain NZP2235, incubated as described above, and then examined by several types of microscopy to document various morphological stages in development of the root nodule symbiosis. Primary host infection of the root epidermis was examined by brightfield and phase contrast light microscopy. Foci of cortical cell divisions were examined by brightfield microscopy after roots were treated by a slightly modified procedure of Truchet et al. (1980). Roots were vacuum infiltrated twice with full-strength Clorox (sodium hypochlorite solution) for $45 \mathrm{~min}$, washed twice with distilled water for 15 min by the same vacuum infiltration procedure, stained briefly with aqueous methylene blue $\left(0.1 \mathrm{mg} / \mathrm{ml}^{-1}\right)$, and examined. Cytology and histology of nodules harvested 21 days after inoculation were examined by combined light and transmission electron microscopy. Nodules were fixed and embedded as described by Subba-Rao et al. (1995). Semithin sections (2 $\mu \mathrm{m})$ were stained with alkaline toluidine blue solution and examine by brightfield light microscopy. Ultrathin sections ( 90 $\mathrm{nm})$ were stained with aqueous uranyl acetate and lead citrate, and examined by transmission electron microscopy. Whole, nodulated roots were examined by stereomicroscopy. Morphometry of selected features was performed by quantitative image analysis with Bioquant System IV software (Dazzo and Petersen 1988).

\section{EMS mutagenesis procedure and screening for symbiotic mutants.}

Five thousand highly inbred seeds were scarified briefly with concentrated sulfuric acid, presoaked in distilled water for $2 \mathrm{~h}$, and then incubated in 0.4 to $1.0 \%$ EMS for 1 to $3 \mathrm{~h}$ at room temperature. The treated seeds were washed under running water for $2 \mathrm{~h}$ and then germinated on top of water-soaked filter papers, as described (Kapranov et al. 1997). Germinated seedlings ( $\mathbf{M}_{1}$ plants) were transferred to pots (two plants per pot), and grown to maturity under controlled greenhouse conditions $\left(18 \mathrm{~h} / 6 \mathrm{~h}\right.$ day/night cycle; $22^{\circ} \mathrm{C} / 18^{\circ} \mathrm{C}$ day/night temperature). $M_{1}$ plants were allowed to self and the $M_{2}$ families of seeds were collected from individual $\mathrm{M}_{1}$ plants. Ten to 15 members per individual $\mathrm{M}_{2}$ family were screened for their symbiotic properties, as follows: Approximately 100 seeds derived from eight $\mathrm{M}_{2}$ families were pooled, surface sterilized, and germinated. Seven-day-old seedlings were inoculated with $M$. loti strain NZP2235 and grown in an N-free mixture of vermiculite and sand, as described (Kapranov et al. 1997). Plants were visually inspected for nodulation 21 days after inoculation with $M$. loti NZP2235. Plants with visible changes in their symbiotic phenotype were transferred to new pots, watered with a nitrogen-rich, modified Hoagland nutrient solution (Hoagland and Arnon 1950), and grown to maturity. The phenotypes of the putative $\mathrm{M}_{2} L$. japonicus mutants were evaluated in the $\mathrm{M}_{3}$ and $\mathrm{M}_{4}$ generations (approximately 50 plants per generation). Selected stable symbiotic mutants analyzed at the $\mathrm{M}_{4}$ generation were used in subsequent genetic analyses.

\section{Genetic analyses.}

Crossing the L. japonicus homozygous (symbiotic) variants with the wild-type Gifu parental line (wt-Gifu) was performed with a manual emasculation and pollination procedure de- scribed previously (Jiang and Gresshoff 1997). The phenotypes of the resulting $F_{1}$ generation were used to determine the genetic basis of the observed phenotype and were further examined by analyzing the segregation patterns in the $\mathrm{F}_{2}$ generation. Forty-five to $800 \mathrm{~F}_{2}$ segregants derived from each mutant $\times$ wt-Gifu cross were analyzed. The $L$. japonicus variants served as female partners in all segregation analyses performed.

To examine allelism, independently isolated monogenic mutants displaying identical or similar phenotypes were crossed, and their respective $F_{1}$ hybrid phenotypes were evaluated.

\section{Acetylene reduction assay.}

The nitrogen fixation capacity of the mutant plants was evaluated by examining their growth in nitrogen-deficient soil. Stunted, chlorotic plants whose growth and yellow phenotype could be rescued by the addition of nitrate to the soil were scored as Fix ${ }^{-}$. In addition, at 21 and 35 days after inoculation, three plants of each mutant line were placed into a $12.5-\mathrm{ml}$ air-tight flask containing $0.5 \mathrm{ml}$ of distilled water to avoid desiccation. The atmosphere of these flasks was enriched with $1 \mathrm{ml}$ of acetylene. After $15 \mathrm{~min}$ of incubation, $1 \mathrm{ml}$ of the resulting atmosphere was sampled and analyzed for acetylene dependent ethylene production by flame-ionization detection (FID) gas chromatography.

\section{RNA gel blot analysis.}

Total RNA was isolated as described earlier (Kapranov et al. 1997). Nodules on the wild-type parent plants, and both nodules and white, nodulelike structures from the mutant lines, were harvested 35 days after inoculation with $M$. loti NZP2235 and immediately frozen in liquid nitrogen. They were subsequently processed and hybridized with $\alpha-{ }^{32} \mathrm{P}-\mathrm{dATP}$ labeled probes as previously described (Kapranov et al. 1997).

\section{ACKNOWLEDGMENTS}

During the initial stages of this work, K. S. visited the laboratory of Jens Stougaard. We thank Jens Stougaard and his collaborators at Aarhus University for providing us with a short introductory course on $L$. japonicus biology and with our initial seed supply. We wish to thank Peter Gresshoff for his helpful suggestions during the course of the work. We also thank the Center for Electron Optics at Michigan State University for use of their facility and Marlene Cameron and Kurt Stepnitz for their help in the preparation of Figures 5 and 6. The research described in this manuscript was supported by grant no. DE-FG0291ER20021 from the Department of Energy and grant no. NSF09630189 from the National Science Foundation.

\section{LITERATURE CITED}

Abe, M., Sherwood, J., Hollingsworth, R., and Dazzo, F. 1984. Stimulation of clover root hair infection by lectin-binding oligosaccharides from the capsular and extracellular polysaccharides of Rhizobium trifolii. J. Bacteriol. 160:517-520.

Ardourel, M., Demont, N., Debelle, F., Maillet, F., de Billy, F., Promé, J.-C., Denarie, J., and Truchet, G. 1994. Rhizobium meliloti lipooligosaccharide nodulation factors: Different structural requirements for bacterial entry into target root hair cells and induction of plant symbiotic developmental responses. Plant Cell 6:1357-1374.

Banaben, V., Duc, G., Lefebvre, V., and Huguet, T. 1995. TE7, An inefficient symbiotic mutant of Medicago truncatula Gaertn. cv. Jamelong. Plant Physiol. 107:53-62.

Bhuvaneswari, T. V., Bhagwat, A. A., and Bauer, W. D. 1981. Transient susceptibility of root cells in four common legumes to nodulation by 
rhizobia. Plant Physiol. 68:1144-1149.

Broughton, W. J., and Dilworth, M. Y. 1971. Control of leghemoglobin synthesis in snake beans. Biochem J. 125:1075-1080.

Caetano-Anolles, G., and Gresshoff, P. M. 1991a. Alfalfa controls nodulation during the onset of Rhizobium-induced cortical cell division. Plant Physiol. 95:366-373.

Caetano-Anolles, G., and Gresshoff, P. M. 1991b. Plant genetic control of nodulation. Annu. Rev. Microbiol. 45:345-382.

Caetano-Anolles, G., Joshi, P. A., and Gresshoff, P. M. 1993. Nodule morphogenesis in the absence of Rhizobia. Pages 297-302 in: New Horizons in Nitrogen Fixation. R. Palacios, J. Mora, and W. E. Newton, eds. Kluwer, Dordrecht, The Netherlands.

Carroll, B. J., MacNeil, D. L., and Gresshoff, P. M. 1985. Isolation and properties of soybean [Glycine $\max (\mathrm{L}$.) Merr.] mutants that nodulate in the presence of high nitrate concentrations. Proc. Natl. Acad. Sci. USA 82:4162-4166.

Carroll, B. J., MacNeil, D. L., and Gresshoff, P. M. 1986. Mutagenesis of soybean [Glycine $\max$ (L.) Merr.] and the isolation of nonnodulating mutants. Plant Sci. 47:109-114.

Cook, R. J., VandenBosch, K., de Bruijn, F. J., and Huguet, T. 1997. Model legume get the nod. Plant Cell 275-281.

Csanadi, G., Szecsi, J., Kalo, P., Kiss, P., Endre, G., Kondorosi, A. Kondorosi, E., and Kiss, G. B. 1994. ENOD12, an early nodulin gene, is not required for nodule formation and efficient nitrogen fixation in alfalfa. Plant Cell 6:201-213.

Dazzo, F. B., Orgambide, G., Philip-Hollingsworth, S., Hollingsworth, R., Ninke, K. D., and Salzwedel, J. 1996. Modulation of development, growth dynamics, wall crystallinity, and infection sites in white clover root hairs by membrane chitolipooligosaccharides from Rhizobium leguminosarum biovar trifolii. J. Bacteriol. 178:3621-3627.

Dazzo, F. B., Truchet, G., Hollingsworth, R., Hrabak, E., Pankratz, A. S., Philip-Hollingsworth, S., Salzwedel, J., Chapman, K., Appenzeller, L., Squartini, A., and Gerhold, D. 1991. Rhizobium lipopolysaccharide modulates infection thread development in white clover root hairs. J. Bacteriol. 173. 5371-5384.

Dazzo, F. B., and Petersen, M. A. 1988. Application of computerassisted image analysis for microscopic studies of the Rhizobiumlegume symbiosis. Symbiosis 7:193-210.

Day, D. A., Lambers, H., Bateman, J., Carroll, B. J., and Gresshoff, P. M. 1986. Growth comparisons of a supernodulating soybean (Glycine max) mutant and its wild type parent. Physiol. Plant. 68:375-382.

de Billy, F., Barker, D. G., Gallusci, P., and Truchet, G. 1991. Leghemoglobin gene transcription is triggered in a single cell layer of the indeterminate nitrogen-fixing root nodule of alfalfa. Plant J. 1:27-35.

de Bruijn, F. J., Wopereis, J., Kapranov, P., Dazzo, F. B., and Szczyglowski, K. 1998. The use of the model legume Lotus japonicus to study nodulation and lateral root formation. Pages 153-163 in: Radical Biology: Advances and Perspectives on the Function of Plant Roots. H. E. Flores, J. P. Lynch, and D. Eissenstat, eds. American Society of Plant Physiologists, Rockville, MD

Delves, A. C., Mathews, A., Day, D. A., Carter, A. S., Carrol, B. J., and Gresshoff, P. M. 1986. Regulation of the soybean-Rhizobium nodule symbiosis by shoot and root factors. Plant Physiol. 82:588-590.

Duc, G., and Messager, A. 1989. Mutagenesis of pea (Pisum sativum L.) and the isolation of mutants for nodulation and nitrogen fixation. Plant Sci. 60:207-213.

Fearn, J. C., and LaRue, T. A. 1991. Ethylene inhibitors restore nodulation to sym5 mutants of Pisum sativum L. cv. Sparkle. Plant Physiol. 96:239-244.

Flemetakis, M., Kavroulakis, P., and Katinakis, P. 1998. ENOD40 gene in L. japonicus. Are the two different ENOD4O genes differentially expressed. Page 336 in: Biological Nitrogen Fixation for the 21st Century. C. Elmerich, A. Kondorosi, and W. E. Newton, eds. Kluwer Academic Pub., Dordrecht, The Netherlands.

Gresshoff, P. M. 1993. Molecular genetic analysis of nodulation genes in soybean. Plant Breed. Rev. 11:275-318.

Handberg, K., and Stougaard, J. 1992. Lotus japonicus, an autogamous, diploid legume species for classical and molecular genetics. Plant J. 2 : 487-496.

Harrison, M. J. 1997. The arbuscular mycorrhizal symbiosis: An underground association. Trends Plant Sci. 2:54-60.

Hirsch, A. M., and LaRue, T. A. 1997. Is the legume nodule a modified root or stem or organ sui generis? Crit. Rev. Plant Sci. 16:361-392.

Hirsch, A. M., and Fang, Y. 1994. Plant hormone and nodulation:
What's the connection? Plant Mol. Biol. 26:5-9.

Hirsch, A. M. 1992. Developmental biology of legume nodulation. New Phytol. 122:211-237.

Hoagland, D. R., and Arnon, D. I. 1950. The water culture method for growing plants without soil. Calif. Agric. Exp. Circ. 337.

Imaizumi-Anraku, H., Kawaguchi, M., Koiwa, H., Akao, S., and Syono, K. 1997. Two ineffective-nodulating mutants of Lotus japonicusDifferent phenotypes caused by the blockage of endocytotic bacterial release and nodule maturation. Plant Cell Physiol. 38:871-881.

Jacobsen, E., and Feenstra, W. J. 1984. A new pea mutant with efficient nodulation in the presence of nitrate. Plant Sci. Lett. 33:337-433.

Jiang, Q., and Gresshoff, P. M. 1997. Classical and molecular genetics of the model legume Lotus japonicus. Mol. Plant-Microbe Interact. 10: 59-68.

Jiang, Q., and Gresshoff, P. M. 1993. Lotus japonicus: A model plant for structure-function analysis in nodulation and nitrogen fixation. Curr Top. Plant Mol. Biol. 2:97-110

Kapranov, P., de Bruijn, F. J., and Szczyglowski, K. 1997. A novel, highly expressed late nodulin gene LjNOD16 from Lotus japonicus. Plant Physiol. 113:1081-1090.

Kneen, B. E., and LaRue, T. A. 1988. Induced symbiosis mutants of pea (Pisum sativum) and sweetclover (Melilotus alba Annua). Plant Sci. 58:177-182.

Kneen, B. E., Weeden, N. F., and LaRue, T. A. 1994. Non-nodulating mutants of Pisum sativum (L.) cv. Sparkle. J. Hered. 85:129-133.

Kosslak, R. M., and Bohlool, B. B. 1984. Suppression of nodule development of one side of a split root system of soybean caused by prior inoculation of the other side. Plant Physiol. 75:125-130.

Lee, K. H., and LaRue, T. A. 1992. Ethylene as a possible mediator of light- and nitrate-induced inhibition of nodulation of Pisum sativum L. cv. Sparkle. Plant Physiol. 100:1334-1338.

Lerouge, P., Roche, P., Faucher, C., Maillet, F., Truchet, G., Promé, J.C., and Denarie, J. 1990 Symbiotic host-specificity of Rhizobium meliloti is determined by a sulfated and acylated glucosamine oligosaccharide signal. Nature 344:781-784.

Mylona, P., Pawlowski, K., and Bisseling, T. 1995. Symbiotic nitrogen fixation. Plant Cell 7:869-885.

Novak, K., Skrdleta, V., Kropacova, M., Lisa, L., and Nemcova, M 1997. Interaction of two genes controlling symbiotic nodule number in pea (Pisum sativum L.). Symbiosis 23:43-62.

Penmetsa, R. V., and Cook, D. R. 1997. A legume ethylene-sensitive mutant hyperinfected by its rhizobial symbiont. Science 275:527-530.

Park, S. J., and Buttery, B. R. 1994. Inheritance of non-nodulation and ineffective nodulation mutants in common bean (Phaseolus vulgaris L.) J. Heredity 85:1-3.

Pierce, M., and Bauer, W. D. 1983. A rapid regulatory response governing nodulation in soybean. Plant Physiol. 73:286-290.

Roche, P., Debelle, F., Maillet, F., Lerouge, P., Faucher, C., Truchet, G. Denarie, J., and Promé, J.-C. 1991. Molecular basis of symbiotic host specificity in Rhizobium meliloti: nodH and nodPQ genes encode the sulfation of lipo-oligosaccharide signals. Cell 67:1131-1143.

Sagan, M., Huguet, T., Barker, D., and Duc, G. 1993. Characterization of two classes of non-fixing mutants of pea plants (Pisum sativum L.). Plant Sci. 95:55-66.

Sagan, M., Morandi, D., Tarenghi, E., and Duc, G. 1995. Selection of nodulation and mycorrhizal mutants in the model plant Medicago truncatula (Gaertn.) after $\gamma$-ray mutagenesis. Plant Sci. 111:63-71.

Schultze, M., Kondorosi, E., Ratet, P., Buire, M., and Kondorosi, A. 1994. Cell and molecular biology of Rhizobium-plant interaction. Int. Rev. Cytol. 156:1-75

Sheng, C., and Harper, J. E. 1997. Shoot versus root signal involvement in nodulation and vegetative growth in wild-type and hypernodulating soybean genotypes. Plant Physiol. 113:825-831.

Spaink, H. P., and Lugtenberg, B. J. J. 1994. Role of rhizobial lipo-chitin oligosaccharide signal molecules in root nodule organogenesis. Plant Mol. Biol. 26:1413-1422.

Streeter, J., and Salminen, S. 1993. Effect of polysaccharide deposition by Bradyrhizobium japonicum bacteroids in soybean nodules on nodules function. Plant Physiol. Biochem. 31:73-79.

Subba-Rao, N. S., Mateos, P. F., Baker, D., Pankratz, H. S., Dazzo, F. B., and Sprent, J. I. 1995. The unique root-nodule symbiosis between Rhizobium and the aquatic legume, Neptunia natans (L.f.) Druce. Planta 196:311-320.

Szczyglowski, K., Hamburger, D., Kapranov, P., and de Bruijn, F. J. 
1997. Construction of a Lotus japonicus late nodulin ESTs library and identification of novel nodule specific genes. Plant Physiol. 114:13351346.

Szczyglowski, K., Wopereis, J., Dazzo, F. B, and de Bruijn, F. J. 1998. Harl, an incomplete dominant mutation in Lotus japonicus, confers aberrant root development and an unusual hypernodulation response (HNR). Pages 305-306 in: Biological Nitrogen Fixation for the 21st Century. C. Elmerich, A. Kondorosi, and W. E. Newton, eds. Kluwer Academic Pub., Dordrecht, The Netherlands.

Truchet, G., Barker, D. G., Camut, S., de Billy, F., Vasee, J., and Huguet, T. 1989. Alfalfa nodulation in the absence of Rhizobia. Mol. Gen. Genet. 219:65-68.

Truchet, G., Michel, M., and Denarie, J. 1980. Sequential analysis of the organogenesis of lucerne (Medicago sativa) root nodules using symbiotically defective mutants of Rhizobium meliloti. Differentiation 16:163-172.

Truchet, G., Roche, P., Lerouge, P., Vasse, J., Camut, S., de Billy, F., Promé, J.-C., and Denarie, J. 1991. Sulphated lipo-oligosaccharide signals of Rhizobium meliloti elicit root nodule organogenesis in alfalfa. Nature 351:670-673.

Turgeon, B., and Bauer, W. D. 1985. Ultrastructure of infection-thread development during the infection of soybean by Rhizobium japonicum. Planta 163:328-349.

Utrup, L. J., Cary, A. J., and Norris, J. H. 1993. Five nodulation mutants of white sweetclover (Melilotus alba Desr.) exhibit distinct phenotypes blocked at root hair curling, infection thread development, and nodule organogenesis. Plant Physiol. 103:925-932.

van Kammen, A. 1984. Suggested nomenclature for plant genes involved in nodulation and symbiosis. Plant Mol. Biol. Rep. 2:43-45.

Vasse, J., de Billy, F., and Truchet, G. 1993. Abortion of infection during the Rhizobium meliloti-alfalfa symbiotic interaction is accompanied by a hypersensitive reaction. Plant J. 4:555-566.

Velazquez, E., Mateos, P. F., Pedrero, P., Dazzo, F. B., and MartinezMolina, E. 1995. Attenuation of symbiotic effectiveness by Rhizobium meliloti SAF22 related to the presence of a cryptic plasmid. Appl. Environ. Microbiol. 61:2033-2036.

Weeden, N. F., Kneen, B. E., and LaRue, T. A. 1990. Genetic analysis of the Sym genes and other nodule-related genes. Pages 323-330 in: Nitrogen Fixation: Achievements and Objectives. P. M. Gresshoff, L. I. Roth, G. Stacey, and W. E. Newton, eds., Chapman and Hall, New York.

Welters, P., Metz, B., Palme, K., Szczyglowski, K., and de Bruijn, F. J. 1993. Interaction of a rhizobial DNA-binding protein with the promoter of a plant leghemoglobin gene. Plant Physiol. 102:1095-1107.

Yang, W.-C., de Blank, C., Meskiene, I., Hirt, H., Bakker, J., van Kammen, A., Franssen, H., and Bisseling, T. 1994. Rhizobium Nod factors reactivate the cell cycle during infection and nodule primordium formation, but the cycle is only completed in primordium formation. Plant Cell 6:1415-1426. 